Acta Theriologica 44 (4): 429-442, 1999.

PL ISSN 0001-7051

\title{
Feeding habits and trophic niche overlap in a Carnivora community of Hungary
}

\author{
József LANSZKI, Sándor KÖRMENDI, Csaba HANCZ \\ and Andrzej ZALEWSKI
}

\begin{abstract}
Lanszki J., Körmendi S., Hancz C. and Zalewski A. 1999. Feeding habits and trophic niche overlap in a Carnivora community of Hungary. Acta Theriologica 44: 429-442.

The seasonal feeding habits of the red fox Vulpes vulpes (Linnaeus, 1758), the stone marten Martes foina (Erxleben, 1777), the stoat Mustela erminea Linnaeus, 1758, the badger Meles meles (Linnaeus, 1758) and the otter Lutra lutra (Linnaeus, 1758) were studied in south-west Hungary, in the course of four years. The habitat conditions, because of human influences, were different in the first and second two years. Diet was examined by scat analysis (238, 262, 67, 50 and 1033 samples, respectively). Small mammals, mainly rodents, were the most important prey for foxes, stone martens and stoats in winter and spring. In summer and autumn insects and fruit were added to fox and marten diet, while birds were added to stoat diet. The badger's main food resources were invertebrates (mainly insects) and maize and, in autumn, rodents. Domestic animals (mainly poultry and rabbit) occurred in the diet of the foxes and martens in all seasons, carcasses (mainly Cervidae) in the diet of these predators and in that of the badgers. The predominant prey of otters was fish, but when the abundance of fish declined, the consumption of amphibians increased. Predation on game birds and hare was not significant. In all seasons, niche overlap was high between foxes, martens and stoats. Niche overlap between these species and the badger increased from spring to autumn. Niche overlap between terrestrial predators and the otter was low. The diet of predators were different between the 1st and 2nd periods.
\end{abstract}

Pannon Agricultural University, Faculty of Animal Sciences, P.O. Box. 16., 7401 Kaposvar, Hungary, e-mail: lanszki@atk.kaposvar.pate.hu (JL, SK, CH); Mammal Research Institute, Polish Academy of Sciences, 17-230 Białowieża, Poland (AZ)

Key words: Carnivora, diet, niche overlap, habitat change, Hungary

\section{Introduction}

Food is a crucial resource for animals and its partitioning among species is important to understand interactions between coexisting species (Schoener 1974, Taper and Marquet 1996). Food partitioning can vary with changes in prey abundance (Goszczyński 1986) or habitat (Clode and Macdonald 1995) or in different geographic sites. In Europe, food, habitat and niche overlap of predators have been investigated in different habitats: boreal (Erlinge 1969, Lindström 1989), temperate deciduous forests (Jędrzejewski et al. 1989, Jędrzejewska and Jędrzejewski 1998), Mediterranean scrubwood and rural areas (Ciampalini and Lovari 1984, Serafini and Lovari 1993), montane forests (Brangi 1995), islands 
(Clevenger 1995, Clode and Macdonald 1995) and lakes and rivers (Wise t al. 1981). Few studies have dealt with diet and niche overlap between predators in habitats changed by human influence (in rural and suburban habitats) especialy in south-eastern Europe (Romanowski and Lesiński 1991, Lanszki and Körnendi 1996a, b).

This paper presents the diet and niche overlap of 5 predatory species: fox Vilpes vulpes (Linnaeus, 1758), the stone marten Martes foina (Erxleben, 1777), the stoat Mustela erminea Linnaeus, 1758, the badger Meles meles (Linnaeus, 1758) and the otter Lutra lutra (Linnaeus, 1758) inhabiting a wetland-forest mosaic habitat typical of south-west Hungary. Our hypothesis was that the degree of competition among predators in a community can differ between the periods investigated in a human-modulated habitat. Different effects can be observed in the case of generalist and specialist species, and the degree of competition is also influenced by habitat changes. We observed (1) the seasonal diet of red fox, stone marten, stoat, badger and otter, (2) the trophic niche overlap between these predators, and (:) the changes of diet and niche overlap related to habitat changes.

\section{Study area}

The Fonó fish pond (FFP) is located in the south-western part of Hungary ( $46^{\circ} 46^{\prime} \mathrm{N}, 17^{\circ} 52^{\prime} \mathrm{E}$ ). The stream feeding the pond belongs to the catchment area of the Kapos river which flows into the Danube. The region is basically a mosaic of arable land, $10-80$ ha of deciduous forests and fish ponds on the nearby waterways.

Our study lasted four years, and the vegetation and the farming conditions were markedly different in the first (December 1991 - November 1993) and second (December 1993 - November 1995) periods investigated in the FFP district (Fig. 1). The main changes in farming conditions in the second part of the study were: the pond was not full and stocked; the nearby forest was partially cut down or thinned, and arable farming was given up for game. The fish fauna of the pond was dominated by the common carp (Cyprinus carpio) and silver carp (Hypophthalamichthys molitrix) in the first two years while in the second period only small sized, economically unimportant fish were present. In the first period the game-field was sown with maize (Zea mays) which was later overtaken by weeds, as were the dry parts of the pond in the second period. The western shore of the pond was covered by 70 ha forest, about 60 year-old Quercetum petraeae-cerris, divided by areas of arable land. In the northem part there was a small meadow, with willows Salicetum triandrae and sedges Caricetum acutiformis-ripariae. One third of the water surface and strip of land around was covered by reeds Scirpo-Phragmiteium. A large area of ploughland in the east, a human settlement with orchards in the south-east and open pasture and pasture with trees (Betula pendula, Robinia pseudo-acacia) in the south bordered the research area.

\section{Material and methods}

The feeding habits of carnivores were investigated by scat and spraint analysis. Scats and spraints were collected every two weeks on a standard route (approx. $4200 \mathrm{~m}$ in length on the $122 \mathrm{ha}$ area). The entire material consisted of 238 scats of red fox, 262 of stone marten, 67 of stoat, 50 of badger, and 1033 spraints of otter. The pine marten has not been observed in our study area. Prey determination was performed by microscope on the basis of feather, bone, scale, pharyngeal teeth, dentition and hair characteristics (eg Berinkey 1966, Debrot et al. 1982, Teerink 1991, Brown et al. 1993). Diet 


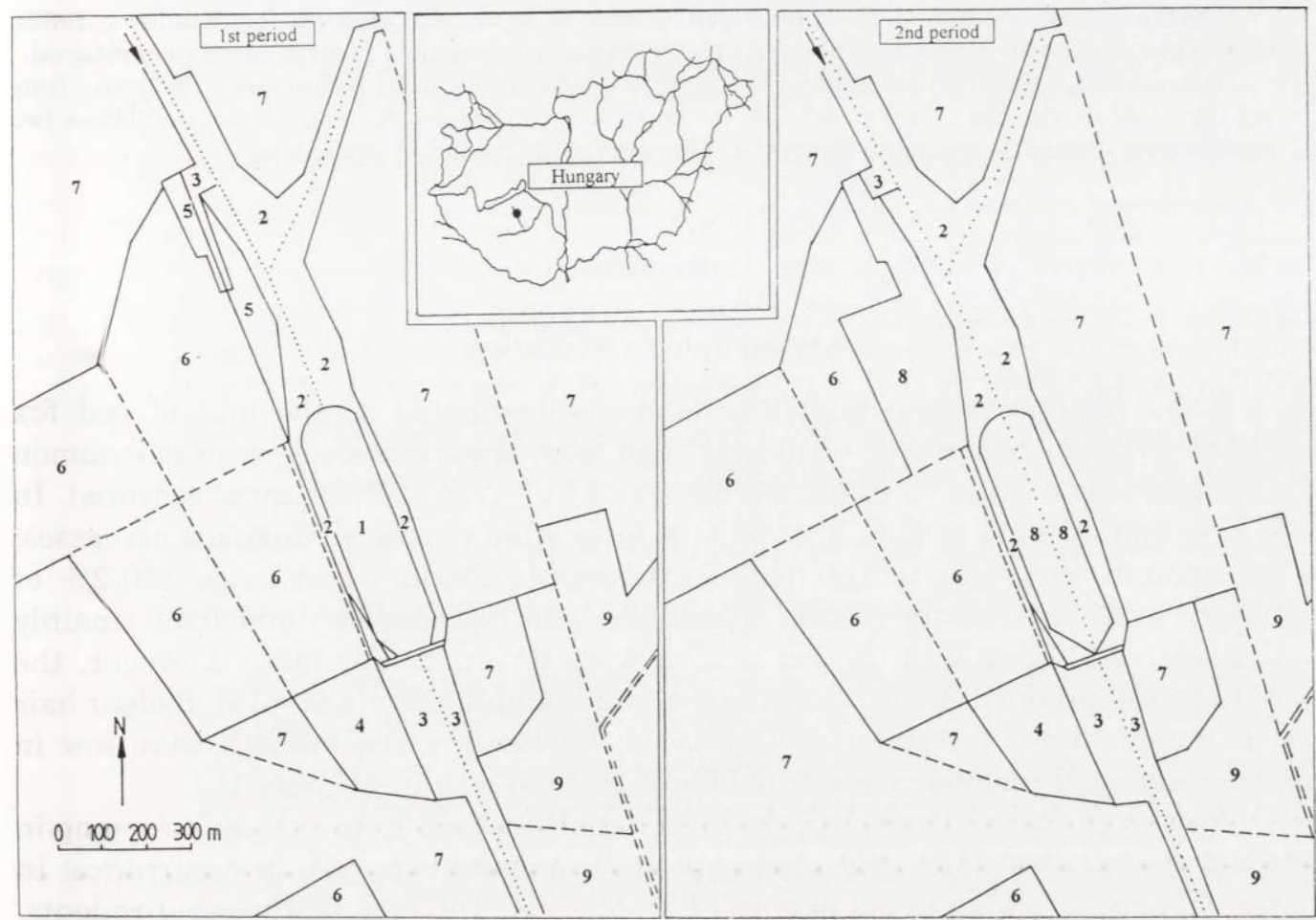

Fig. 1. Habitat types in the Fonó fish pond region in the first (1st) and second (2nd) periods; 1st period: December 1991-November 1993; 2nd period: December 1993-November 1995. Numbering: 1 - water surface (in 1st period 7.4\%, and in 2nd period 0.8\%), 2 - reed + bulrush (17.2 and 18.9\%), 3 - meadow + willow ( 7.4 and $6.6 \%), 4$ - pasture with trees (4.9 and $4.9 \%), 5$ - game field (2.4 and $0 \%), 6$ - forest (32.8 and $26.2 \%$ ), 7 - ploughland (27.9 and $27.9 \%$ ), 8 - weed communities ( 0 and $14.8 \%), 9$ - village, $==-$ road. The difference between the two periods was significant $\left(\chi^{2}=31.15\right.$, df $\left.=7, p<0.0001\right)$.

composition and niche overlap were calculated from the relative occurrence of food components in the scats.

Food taxons applied in the calculations were: (1) small mammals: Insectivora, Lagomorpha and Rodentia; (2) carcasses: Artiodactyla and Carnivora; (3) domestic animals; (4) birds; (5) reptiles and amphibians; (6) fish; (7) invertebrates: insects, earthworms and molluscs (Gastropoda); (8) plant material. Non-organic material was not taken into account in the calculations. In some scats the carnivore's own hair was found. This presumably originated from cleaning and not feeding and so was disregarded.

Calculations of the food niche breadth $\left[B=1 / \Sigma p_{i}^{2}\right.$, where $p_{i}=$ percentage occurrence of general prey taxa] were made in accordance with Levins (1968), whereas those of the standardized niche breadth $\left[B S=\left(B-B_{\min }\right) /\left(B_{\max }-B_{\min }\right)\right.$, where $B_{\min }=$ minimum value of niche breadth $(=1) ; B_{\max }=$ maximum value of niche breadth ( = number of general prey taxa)] were made in accordance with Colwell and Futuyma (1971). Calculation of the food niche overlap $\left[\mathrm{O}_{j \mathrm{k}}=1-0.5 \Sigma\left|\mathrm{p}_{\mathrm{ij}}-\mathrm{p}_{\mathrm{ik}}\right|\right.$, where $\mathrm{p}_{\mathrm{ij}}=$ percentage occurrence of general prey taxa (i) in the " $\mathrm{j}$ " Carnivora's diet, $\mathrm{p}_{\mathrm{ik}}=$ percentage occurrence of general prey taxa (i) in the "k" carnivore's diet], were in accordance with Schoener $(1968,1974)$. Food components by scat (i/s) were used to express the relative diversity of food, where i - total item occurrence and $\mathrm{s}$ - total scat number. 
The data were evaluated by $\chi^{2}$-test and cluster analysis (SPSS 5.0.1 for Windows 1992). Hierarchical cluster analysis was performed by between-group linkage and Pearson correlation interval.

The data from the first and second years (1st period: December 1991 - November 1993) and from the third and fourth years (2nd period: December 1993 - November 1995) were combined. These two periods were evaluated separately because of the significant changes of the habitat.

\section{Results}

\section{Seasonal diet composition}

From autumn to spring small mammals dominated in the diet of red fox (37.8-49.1\% of occurrence - Table 1). The most important prey was the common vole Microtus arvalis (\% of occurrence was $21.9-27.8$ in these three seasons). In winter and spring, in addition to rodents, foxes often consumed ungulate carcasses; in autumn they frequently took fruit, mainly Prunus domestica $(10.2 \%$ of occurrence). In summer insects (Carabidae and Scarabeidae) and fruit (mainly Cerasus avium, with $13.1 \%$ occurrence) were important for foxes; however, the data on the summer diet were based on a small sample of scats $(n=19)$. Badger hair was found in red fox scats in all seasons. Values of niche breadth were low in autumn (small mammals and fruit) and higher in summer (Table 1).

As with the fox rodents were the most important food from autumn to spring in the stone marten's diet; these prey species composed over $35 \%$ of occurrence. In summer rodents were found in only $17.8 \%$ of scats (Table 1). Of the other rodents, black rat Rattus rattus and house mouse Mus musculus were found only in the stone marten's diet. In general, birds were more important in winter and spring, insects in spring and summer and fruit in summer and autumn (Table 1). Of the birds, marten often took passerines, but also bigger species such as pheasants Phasianus colchicus. Insect species taken by martens were mainly beetles from the Carabidae family. The fruit taken changed from summer to autumn: in the former the marten frequently took cherries Cerasus avium (25.1\% occurrence), and in the latter grapes Vitis vinifera ( $16.3 \%$ occurrence). Niche breadth varied slightly between seasons: $3.1-3.8$ (Table 1).

The sample size for stoats was very small because animals occurred only in a restricted area. In each season two prey types were commonly identified from stoat scats: rodents (dominated by mice Apodemus sp. and voles Microtus sp.) and birds (Passeriformes) (Table 1). The food spectrum of stoat was the narrowest among the species investigated in all seasons. The relative variety of the diet (i/s) $1.3-1.7$ and the niche breadth was found to be between 1.5-3.3.

Out of 77 scats of foxes, martens and stoats including Apodemus remains the species was determined in 66 cases; $94 \%$ were yellow-necked mouse Apodemus flavicollis and only $3 \%$ striped field mouse A. agrarius and $3 \%$ wood mouse A. sylvaticus.

The spring diet of the badger was dominated by invertebrates, mainly insects (Carabidae spp. - 43.5\%) and earthworms $(21.2 \%$ - Table 1$)$. There was a 


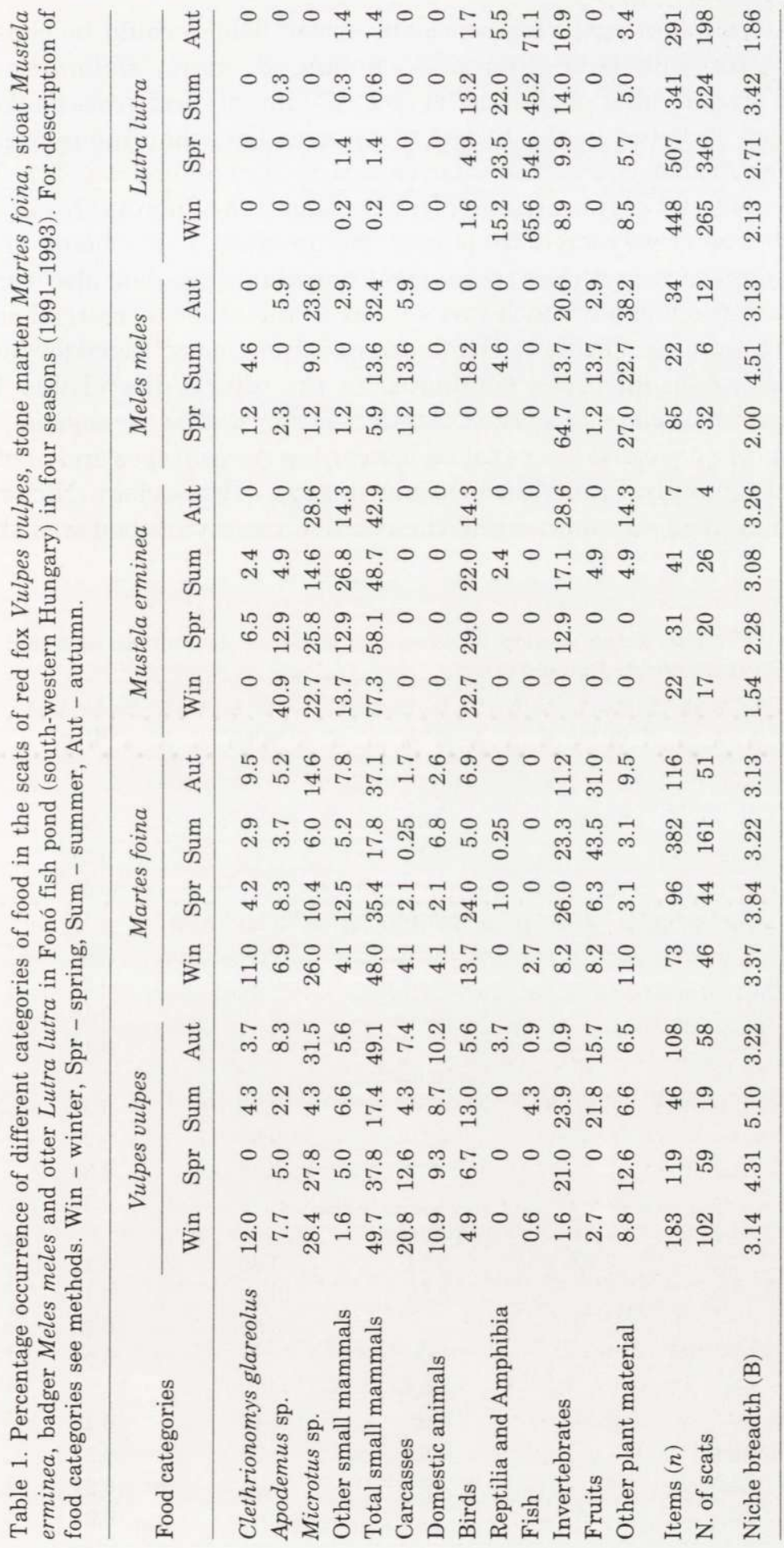


significant ratio of plant material, especially maize, which could be consumed at feeding dumps for wild boar. Plants (C. avium, Z. mays, Helianthus annus) dominated the summer diet of the badger (36.3\%). Insects and grass snake (Natrix natrix) eggs also occurred in the badger's summer diet when niche breadth was found to be high (Table 1 ), and the relative variety (i/s) of food was 3.7 . The most significant part (41.1\%) of the autumn diet also consisted of plants (Z. mays). Small mammals had a relatively high frequency, the greatest value being that of $M$. arvalis (26.7\%) but carcasses (Sus scrofa and Capreolus capreolus) also occurred. In autumn the badger's niche breadth was similar to the other terrestrial carnivores and lower than in summer (Table 1). Winter samples were not collected for the badger.

In all seasons fish and frogs dominated in the otter's diet (Table 1). Small mammals (Sorex sp., Lepus europaeus, Apodemus sp., Rattus norvegicus, Ondatra zibethicus, Arvicola terrestris) were taken in very low percentages and of other prey otters ate birds (mainly Passeriformes) and insects (Dytiscidae). Niche breadth values were highest in summer, while the relative variety of food was the lowest (Table 1).

Table 2. Trophic niche overlap between five predators in four seasons and annually (data pooled from 4 years).

\begin{tabular}{lcccc}
\hline Species & Stone marten & Stoat & Badger & Otter \\
\hline & & Winter & & \\
Red fox & 0.75 & 0.55 & - & 0.13 \\
Stone marten & & 0.62 & - & 0.21 \\
Stoat & & Spring & - & 0.02 \\
Red fox & 0.77 & 0.57 & 0.45 & 0.22 \\
Stone marten & & 0.72 & 0.43 & 0.21 \\
Stoat & & & 0.19 & 0.16 \\
Badger & & & & 0.17 \\
& & Summer & & \\
Red fox & 0.81 & 0.57 & 0.75 & 0.37 \\
Stone marten & & 0.50 & 0.69 & 0.25 \\
Stoat & & & 0.58 & 0.35 \\
Badger & & & & 0.37 \\
Red fox & 0.70 & Autumn & & \\
Stone marten & & 0.64 & 0.62 & 0.12 \\
Stoat & & 0.69 & 0.85 & 0.16 \\
Badger & & & 0.59 & 0.20 \\
Red fox & & & & 0.22 \\
Stone marten & 0.65 & Annual & & \\
Stoat & & 0.65 & 0.46 & 0.23 \\
Badger & & 0.54 & 0.70 & 0.24 \\
\hline & & & 0.35 & 0.24 \\
& & & & 0.22 \\
\hline & & & &
\end{tabular}




\section{Trophic niche overlap}

Niche overlap values among the terrestrial predators (red fox, stone marten, stoat) were high (>0.5) and varied between seasons (Table 2, Fig. 2). All of them took the small mammals moving on the soil surface. The red fox and the stone marten have a similar diet and habitat (eg they often visit villages), and the niche overlap is high in all seasons (the highest in summer). This mainly depends on the consumption of small mammals and birds. Niche overlap between stoat and fox was moderate in all seasons, but was generally higher between the stoat and the marten. Niche overlap between the letter two predators was highest in spring, when both stoat and marten have young, and lowest in summer (Table 2, Fig. 2).

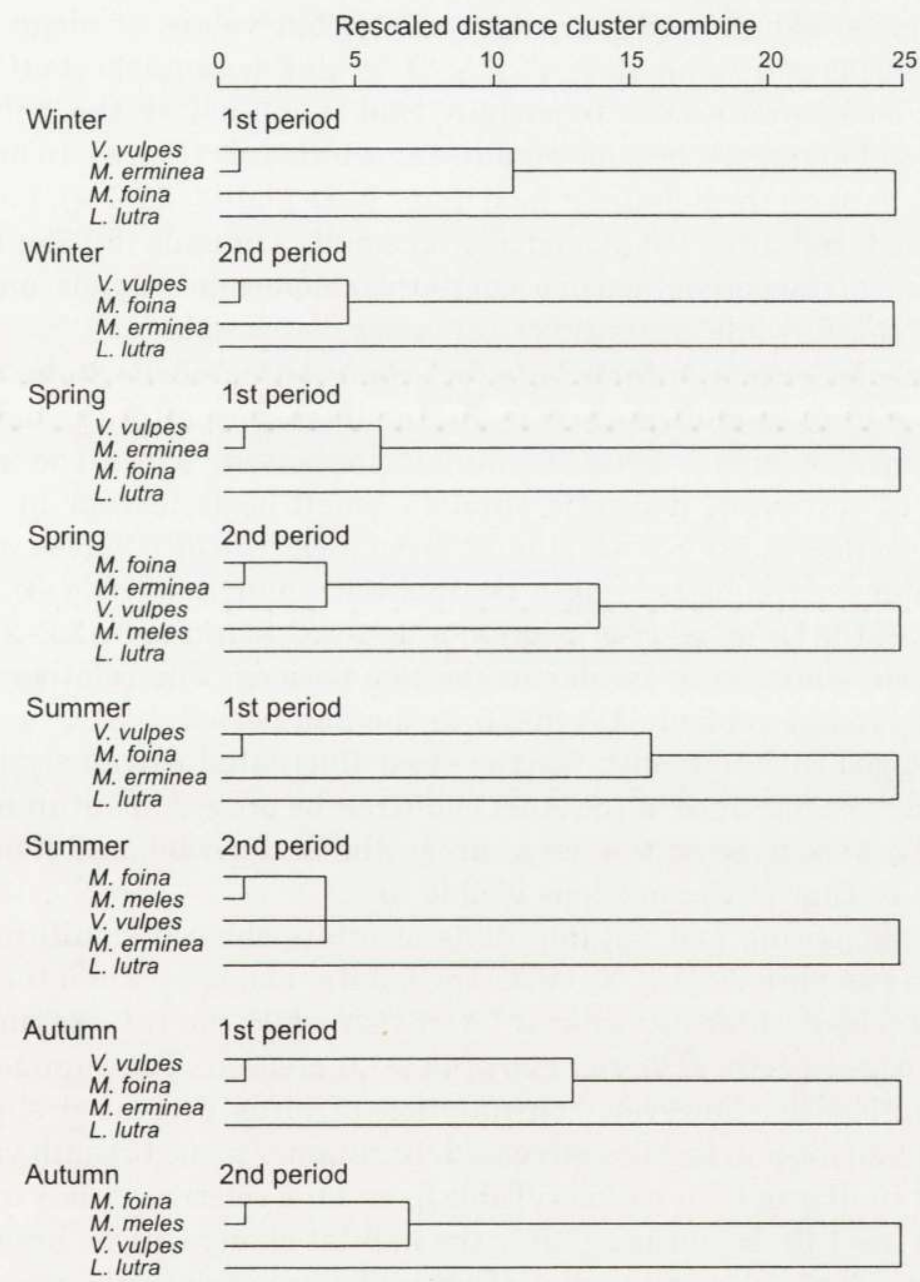

Fig. 2. Dendogram of diet similarity in the Carnivora community, calculated with hierarchical cluster analysis. 
Niche overlap between the badger and the other terrestrial carnivores increased from spring to autumn, the overlap being the highest with the marten. The otter, as an aquatic predator, has a diet different from that of terrestrial predators and so showed low overlap with them (Table 2, Fig. 2).

\section{Diet composition and habitat changes}

The diet of red fox was not significantly different between the 1st and 2nd periods, in summer, but differed in all other seasons (Fig. 3). In winter and autumn in the 2nd period the standardized niche breadth and the relative variety of food in the red fox diet declined. In summer before the habitat changes, Muscardinus avellanarius was an important prey, C. glareolus and $M$. arvalis following. In spring the fox's diet showed a greater variety, but values of niche breadth were similar in the 1st and 2nd periods (Table 3). In this season insects (Carabidae spp. Melolontha melolontha) were important food items before the habitat changes, birds and small mammals became significant afterwards (Fig. 3 ). In autumn, before the habitat changes, the dominant food items were plants (55.2\%), mainly fruits; in the 2nd period, red foxes fed principally on small mammals (59.5\%; Fig. 3). In the 2nd period, also, the percentage of occurrence of domestic animals, amphibians and reptiles increased, while the ratio of carcasses decreased.

In all seasons, except autumn, the diet composition of the stone marten in the two periods differed significantly (Fig. 3). In all seasons, after the habitat changes, the occurrence of small forest mammals increased, while the percentage of occurrence of carcasses, domestic animals, small birds (except in summer) and plant material decreased. Spring standardized niche breadth values were lower and summer values were higher after the habitat changes (Table 3 ). The relative variety (i/s) of the stone marten's summer diet was found to be 2.2-2.5. In autumn niche breadth values were similar in the two periods. The relative variety of the autumn food increased from 1.8 to 2.3 in the 2 nd period.

Standardized niche breadth for the stoat fluctuated extremely in the periods investigated. The presence of the stoat could not be proved in autumn of the second period. Badger occurred in the area only in the 2nd period, and its niche breadth was similar to that of the martens (Table 3).

The winter, spring and autumn diets of otters showed significant differences between the two periods (Fig. 3). After the habitat changes (when the pond was not filled and stocked), otters consumed fewer fish while the ratio of amphibians and insects (eg water beetle Dytiscus marginalis) increased. The summer diet did not change significantly; however, consumption of birds decreased slightly and the ratio of amphibians and reptiles increased. In summer niche breadth values were the highest and similar in both periods (Table 3 ) and the relative variety of food (i/s) was the lowest (1.5-1.6). In autumn, after the habitat change, niche breadth increased significantly (Table 3 ) and the diet of otters became relatively more diversified.

Niche overlap between fox and marten, after the habitat change, increased only in winter (from 0.56 to 0.75 ), while in summer and autumn this decreased (from 0.8 

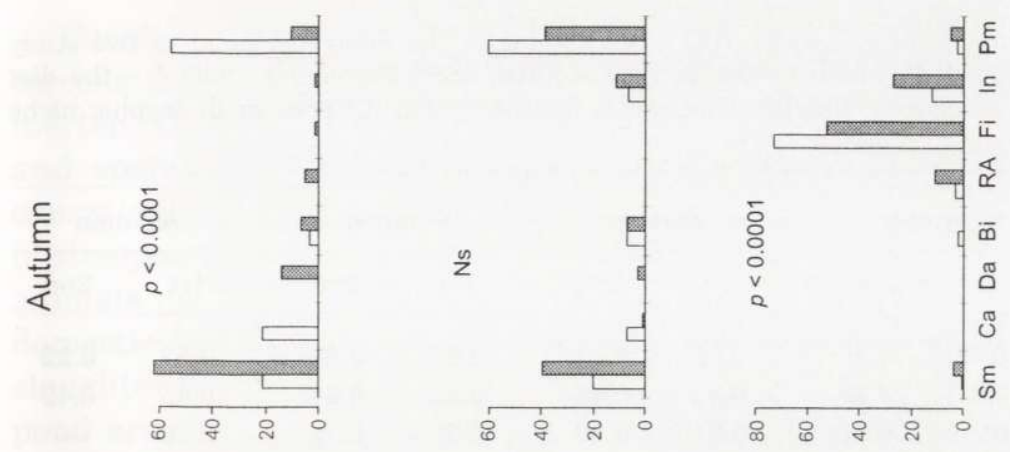

号

?

药

on

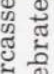

สํ

1)

สิ 1

드

胥
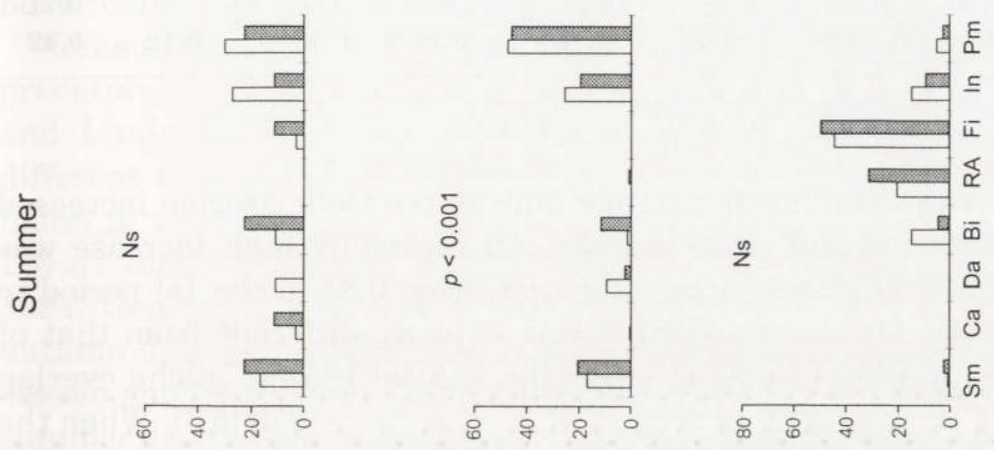

สี

क्ष फ़

เ 종

की

ธี छั

ซึ 응

ํㅕㅇ

훙.

5 15

द्ध

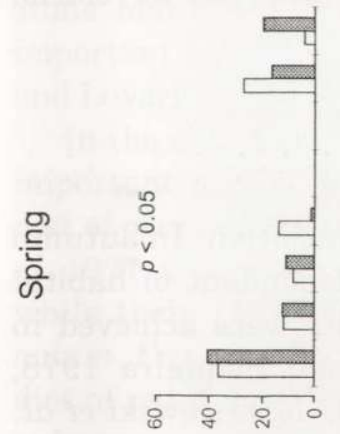
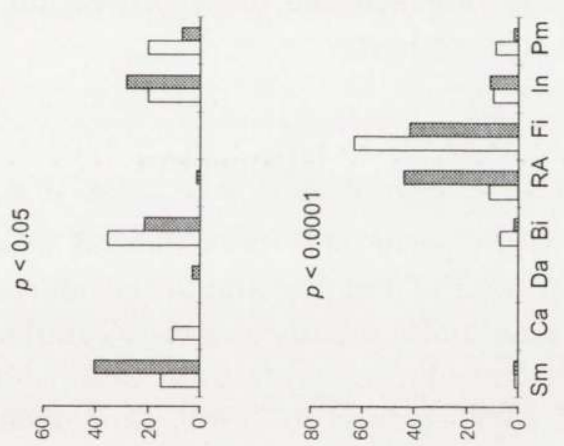

की

궁

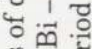

范

ฏ.

응

亏3

$\Phi$

淽

कึ 웡

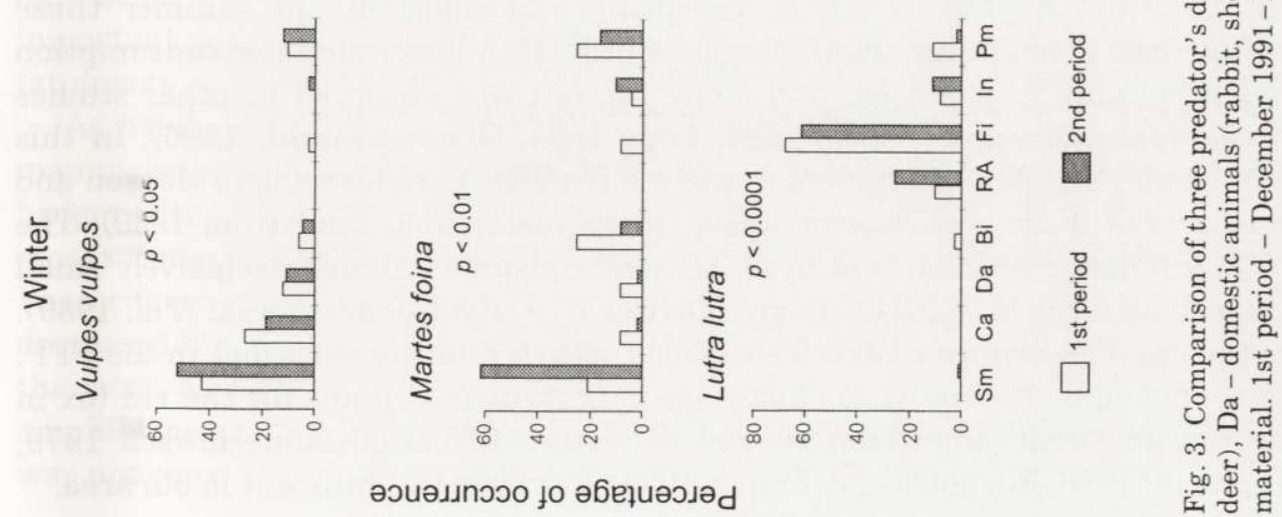


Table 3. Standardized trophic niche breadth $(\mathrm{Bs})$ of carnivores in the Fonó fish pond in two study periods: 1st - December 1991-November 1993; 2nd - December 1993-November 1995. * - the diet contained only two food categories. Boldfaced numerals indicated high differences in trophic niche breadth between the 1 st and 2 nd period.

\begin{tabular}{|c|c|c|c|c|c|c|c|c|}
\hline \multirow{2}{*}{ Species } & \multicolumn{2}{|c|}{ Winter } & \multicolumn{2}{|c|}{ Spring } & \multicolumn{2}{|c|}{ Summer } & \multicolumn{2}{|c|}{ Autumn } \\
\hline & 1 st & 2nd & 1 st & 2nd & 1 st & 2nd & 1 st & 2nd \\
\hline Vulpes vulpes & 0.50 & 0.40 & 0.62 & 0.62 & 0.62 & 0.88 & 0.52 & 0.22 \\
\hline Martes foina & 0.21 & 0.28 & 0.84 & 0.49 & 0.42 & 0.66 & 0.45 & 0.42 \\
\hline Mustela erminea & $0^{*}$ & 0.98 & 0.81 & 0.46 & 0.70 & 0.72 & 0.76 & - \\
\hline Meles meles & - & - & - & 0.33 & - & 0.70 & - & 0.71 \\
\hline Lutra lutra & 0.26 & 0.30 & 0.27 & 0.34 & 0.38 & 0.36 & 0.12 & 0.42 \\
\hline
\end{tabular}

to 0.6 ) and in spring it was similar. In summer and winter niche overlap increased between stoat and both fox and stone marten. An especially high increase was observed between stoat and stone marten (summer: from 0.34 in the 1 st period to 0.76 in the 2 nd period). The otter's feeding was strongly different from that of terrestrial carnivores in all seasons and, after the habitat change, niche overlap between the otter and these predators decreased in all seasons (Table 3 ). When the pond was not filled and stocked the otter preyed on frogs, whereas terrestrial predators frequently took rodents.

\section{Discussion}

The composition of the predators' diets showed seasonal variation. In autumn and winter, the main food of red fox and stone marten, independent of habitat changes, was small mammals, mainly rodents. Similar results were achieved in other areas for these predators (Englund 1965, Jensen and Sequeira 1978, Goszczyński 1986, Papageorgiou et al. 1988, Lindström 1989, Jędrzejewski et al. 1989, Serafini and Lovari 1993). In spring and especially in summer these predators consumed fewer small mammals in FFP. A lower summer consumption of small mammals by red fox and stone marten was observed in other studies (Jędrzejewski and Jędrzejewska 1992, Lode 1994, Genovesi et al. 1996). In this season small mammals dominated in the red fox diet in many regions (Jensen and Sequeira 1978, Kolb and Hewson 1979, Goszczyński 1986, Lindström 1989). The stoat is a rodent specialist and in all seasons consumed almost exclusively small mammals, its niche breadth being low (Debrot et al. 1984, Jędrzejewski et al. 1989). Nonetheless, Passeriformes and insects also occurred in the stoat diet in the FFP. Lagomorpha and Phasianus colchicus are important food items for the red fox in areas rich in small game (Jensen and Sequeira 1978, Kolb and Hewson 1979, Goszczyński 1986, Reynolds and Tapper 1995), but were insignificant in our area. 
Carnivores appearing in the diet of the red fox (M. meles) could originate from carcass consumption (Englund 1965), and this can also be applied to the stone marten. Carcasses were rarely found in the diet of omnivores compared to winter and spring samples. The carcasses of ungulates (mainly roe deer Capreolus capreolus) were important food in winter for red fox in FFP and in other regions (Jędrzejewski and Jędrzejewska 1992). Foxes scavenge on carcasses of domestic animals not only in winter but also in other seasons. The relatively high ratio of domestic animals in the diet of the fox and stone marten can be explained by winter slaughter (Jensen and Sequeira 1978) and by the reduced food sources of the fish pond area. The fox and stone marten differ from stoat, badger and otter, which never consumed domestic animals in our area.

Consumption of invertebrates (mainly insects) was important for terrestrial predators in spring and summer, similary to the findings of Ryszkowski et al (1971) and Lindström (1989). In Europe seasonal consumption of insects varies in different regions. In Mediterranean areas a high proportion of insects has been found in the diets of red fox, stone marten and badger in winter (Ciampalini and Lovari 1984, Serafini and Lovari 1993) and in France and Italy in summer (Lode 1994, Genovesi et al. 1996). A high proportion of insects have been found in the autumn diets of fox and marten in Poland and Denmark (Ryszkowski et al. 1971, Jensen and Sequeira 1978). In FFP insects (Carabidae spp.) were significant in the summer diet of the red fox and stone marten; Lucanus cervus was consumed by the stone marten, the aquatic Dytiscus marginalis by the otter. Earthworms were important only in spring in the badger's diet, but in other investigations (Ciampalini and Lovari 1984, Kruuk 1989) this item was found to be significant in other seasons.

In the summer and autumn, when fruits are ripening, plant material played an important part in the diet of red fox, stone marten and badger. Plants occur in the diet of carnivores at high frequency in central and southern Europe (Ryszkowski et al. 1971, Ciampalini and Lovari 1985, Goszczyński 1986, Papageorgiou et al. 1988) while their role is less significant in northern areas (Lindström 1989). Cerasus avium, Fragaria sp. and Prunus domestica were the most important species in the diet of red fox and stone marten and Z. mays in the badger's food. Otter consumed only some water plants (Typha, Carex, Lemna sp.). Plants, principally fruits, are important sources of carbohydrates, contributing to the formation of subcutaneous fat depcts and so helping in successful wintering.

As habitat changes resulted in an expansion of weed communities some small mammals (eg $M$. arvalis) became more significant in the autumn diet of red fox and badger. Stone marten fed on forest species (Apodemus spp., C. glareolus) while stoats consumed Insectivora species. The consumption of birds (principally Passeriformes) by red fox and stone marten increased after the habitat changes but decreased for stoat and otter. The habitat changes affected the food sources of otter the most, as its dominant food, fish, decreased drastically. Otters consumed more amphibians and reptiles when the fish pond was not stocked. The presence of otters was not constant after the habitat changes, as indicated by the reduced number of 
spraints, mainly in summer (Lanszki and Körmendi 1996b). The otters directed their alteration towards frogs and aquatic insects. It seems the otter does not leave its habitat if the main food (fish) diminishes, provided an alternative food source (amphibians) can be found.

In winter and spring the trophic niche overlap of red fox and stone marten was 0.7 in Italy (Serafini and Lovari 1993) and 0.7-0.9 in Poland (Goszczyński 1986). Our investigations resulted in similarly high values. These two species use basically the same food sources (rodents, carcasses, domestic animals, insects) in winter and in spring. Habitat changes caused a significant increase in trophic niche overlap of terrestrial carnivores in summer and autumn, this overlap having been moderate in the 1st period. The omnivores (red fox, stone marten and badger) used principally the same food sources. High trophic niche overlap observed by Ciampalini and Lovari (1984) between red fox and badger (0.77) was lower in our area because of the different ecological factors. In our area badger is an important insect and plant material consumer and red fox is not, and presumably the habitat changes affected the feeding places of badger the least.

Habitat changes occurred in areas which were important places of feeding for stone marten and stoat in the 1st period and the niche breadth of these species diminished in winter and also in spring. Niche overlap was higher between red fox and stoat and increased in the 2 nd period. Similar niche overlap (0.43) was found between fox and stoat in a forested area by Jędrzejewski et al. (1989). The effects of habitat changes could be disadvantageous for stoat, because niche overlap between the stoat and the red fox and stone marten is increasing. The stoat had probably abandoned its original territories, as no signs of its presence were found after the habitat changes, and badger appeared in the area investigated in the second period. We suggest that changes of habitat, that is the giving up fish pond and game field cultivation as well as the cutting of forest, influence the structure of a Carnivora community and interspecific relations. Summarizing our results, since trophic niche overlap increased among terrestrial predators, the presence of the stoat became unstable. Generalist species (fox, stone marten) and otter can adapt to habitat changes, as manifested in diet changes and distribution of the food resources. The small sized rodent-specialist stoat had to face competition for a similar source of food accompanied by disadvantageous habitat changes.

Acknowledgements: We would like to thank D. Moss and P. Duncan for correcting the English. The comments of three anonymous referees were of great help during revision. This work was supported by the Hungarian Research Fund (OTKA, grant no. F 23057). A. Zalewski was a recipient of the National Fellowship '97 from the Foundation for Polish Science.

\section{References}

Berinkey L. 1966. [Halak - Pisces]. Akadémiai Kiadó, Budapest: 1-138. [In Hungarian]

Brangi A. 1995. Seasonal changes of trophic niche overlap in the stone marten (Martes foina) and the red fox (Vulpes vulpes) in a mountainous area of the northern Alpennines (N-Italy). Hystrix 7 : $113-118$. 
Brown R., Ferguson J., Lawrence M. and Lees D. 1993. Federn, Spuren \& Zeichen der Vögel Europas: Ein Feldführer. Aula- Verlag, Wiesbaden: 1-232.

Ciampalini B. and Lovari S. 1985. Food habits and trophic niche overlap of the Badger (Meles meles L.) and the Red fox (Vulpes vulpes L.) in a Mediterranean coastal area. Zeitschrift für Säugetierkunde 50: 226-234.

Clevenger A. P. 1995. Seasonality and relationship of food resources use of Martes martes, Genetta genetta and Felis catus in the Balearic Island. Revue D'Ecologie: la Terre et la Vie 50: 109-131.

Clode D. and Macdonald D. W. 1995. Evidence for food composition between mink (Mustela vison) and otter (Lutra lutra) on Scottish island. Journal of Zoology, London 237: 435-444.

Colwell R. K. and Futuyma D. J. 1971. On the measurement of niche breadth and overlap. Ecology 52: 567-576.

Debrot S., Fivaz G. and Mermod C. 1984. Note sur le gite et la nourriture hivernale d'une hermine (Mustela erminea L.). Bulletin de la Société nauchateloise des Sciences naturelles 107: 137-141.

Debrot S., Fivaz G., Mermod C. and Weber J.-M. 1982. Atlas des poils des mammiferes d'Europe. Institut de Zoologie, Neuchâtel: 1-208.

Englund J. 1965. Studies on food ecology of the red fox (Vulpes v.) in Sweden. Viltrevy 3: 377-485.

Erlinge S. 1969. Food habits of the otter Lutra lutra L. and the mink Mustela vison Schreber in a trout water in southern Sweden. Oikos 20: 1-7.

Genovesi P., Secchi M. and Boitani L. 1996. Diet of stone martens: an example of ecological flexibility. Journal of Zoology, London 238: 545-555.

Goszczyński J. 1986. Diet of foxes and martens in central Poland. Acta Theriologica 31: 491-506.

Jędrzejewska B. and Jẹdrzejewski W. 1998. Predation in vertebrate communities. The Białowieża Primeval Forest as a case study. Springer-Verlag, Berlin, Heildelberg, New York: 1-450.

Jędrzejewski W. and Jędrzejewska B. 1992. Foraging and diet of the red fox Vulpes vulpes in relation to variable food resources in Białowieża National Park, Poland. Ecography 15: 213-221.

Jędrzejewski W., Jędrzejewska B. and Szymura A. 1989. Food niche overlaps in a winter community of predators in the Białowieża Primeval Forest, Poland. Acta Theriologica 34: 487-496.

Jensen B. and Sequeira D. M. 1978. The diet of the red fox (Vulpes vulpes L.) in Denmark. Danish Review of Game Biology 10: 1-16.

Kolb H. H. and Hewson R. 1979. Variation in the diet of foxes in Scotland. Acta Theriologica 24: 69-83.

Kruuk H. 1989. The social badger. Oxford University Press, Oxford: 1-155.

Lanszki J. and Körmendi S. 1996a. Otter diet in relation to fish availability in a fish pond in Hungary. Acta Theriologica 41: 127-136.

Lanszki J. and Körmendi S. 1996b. Examination of food ecology of four carnivorous species in the district of Fonó fish-pond (Somogy county). Állattani Közlemények 81: 73-85 [In Hungarian with English summary]

Levins R. 1968. Evolution in changing environment. Princeton University Press, Princeton: 1-120.

Lindström E. 1989. The role of medium-sized carnivores in the Nordic boreal forest. Finnish Game Research 46: 53-63.

Lode T. 1994. Feeding habits of the stone marten Martes foina and environmental factors in western France. Zeitschrift für Säugetierkunde 59; 189-191.

Papageorgiou N. K., Sepougaris A., Christopoulou O. G., Vlachos C. G. and Petamidis J. S. 1988. Food habits of the red fox in Greece. Acta Theriologica 33: 313-324.

Reynolds J. C. and Tapper S. 1995. The ecology of the red fox Vulpes vulpes in relation to small game in rural southern England. Wildlife Biology 1: 105-119.

Romanowski J. and Lesiński G. 1991. A note on the diet of stone marten in southeastern Romania. Acta Theriologica 36: 201-204.

Ryszkowski L., Kenyon Wagner C., Goszczyński J. and Truszkowski J. 1971. Operation of predators in a forest and cultivated fields. Annales Zoologici Fennici 8: 160-168.

Schoener T. 1968. The Anolis lizards of Bimini: resource partitioning in a complex fauna. Ecology 49: 704-726.

Schoener T. 1974. Resource partitioning in ecological communities. Science 185: 27-39. 
Serafini P. and Lovari S. 1993. Food habits and trophic niche overlap of red fox and the stone marten in a Mediterranean rural area. Acta Theriologica 38: 233-344.

SPSS For Windows 1992. Version 5.0.1, Copyright SPSS Inc.

Taper M. L. and Marquet P. A. 1996. How do species really divide resources? The American Naturalist 147: 1072-1082.

Teerink B. J. 1991. Hair of West-European mammals. Cambridge University Press, Cambridge: 1-224.

Wise M. H., Linn I. J. and Kennedy C. R. 1981. A comparison of the feeding biology of mink Mustela vison and otter Lutra lutra. Journal of Zoology, London 195: 181-213.

Received 3 June 1998, revised 16 June 1999, accepted 16 June 1999. 